\title{
Understanding the logics of pheromone processing in the honeybee brain: from labeled-lines to across-fiber patterns
}

\author{
Jean-Christophe Sandoz*, Nina Deisig, Maria Gabriela de Brito Sanchez and Martin Giurfa \\ Research Center for Animal Cognition, CNRS - University Paul Sabatier, Toulouse Cedex 9, France \\ Edited by: Carmen Sandi, Ecole Polytechnique Federale De Lausanne, Switzerland \\ Reviewed by: C. G. Galizia, Universität Konstanz, Germany \\ Alberto Ferrus, Cajal Institute CSIC, Spain
}

Honeybees employ a very rich repertoire of pheromones to ensure intraspecific communication in a wide range of behavioral contexts. This communication can be complex, since the same compounds can have a variety of physiological and behavioral effects depending on the receiver. Honeybees constitute an ideal model to study the neurobiological basis of pheromonal processing, as they are already one of the most influential animal models for the study of general odor processing and learning at behavioral, cellular and molecular levels. Accordingly, the anatomy of the bee brain is well characterized and electro- and opto-physiological recording techniques at different stages of the olfactory circuit are possible in the laboratory. Here we review pheromone communication in honeybees and analyze the different stages of olfactory processing in the honeybee brain, focusing on available data on pheromone detection, processing and representation at these different stages. In particular, we argue that the traditional distinction between labeled-line and across-fiber pattern processing, attributed to pheromone and general odors respectively, may not be so clear in the case of honeybees, especially for social-pheromones. We propose new research avenues for stimulating future work in this area.

Keywords: pheromones, odor processing, labeled-line, across-fiber pattern, social insect, antennal lobe, mushroom body, lateral horn

\section{INTRODUCTION}

The fundamental importance of chemical communication in biological systems has been long established. Olfactory signals play a vital role in most animal groups both for their survival and reproduction. Thus, sexual partners are often located via sex pheromones that can be detected on the basis of very few molecules. Food sources or dangers can be detected by olfactory cues, which can be learned by animals as predictors for these outcomes. In other cases, reliable food sources can be marked by means of attractive pheromones, conspecifics can be gathered or dispersed using aggregation or repellent pheromones, respectively, and potential enemies or noxious events can be signalized by means of alarm pheromones. In all of these behaviors, the olfactory system is indispensable.

Pheromones are volatile chemicals used for communication between individuals of the same species. Karlson and Luscher (1959) first defined them as "... substances which are secreted to the outside by an individual and received by a second individual of the same species, in which they release a specific reaction, for example, a definite behaviour or a developmental process". Later, the definition was modified in order to incorporate the beneficial aspect of intraspecific communication that pheromones mediate (Rutowski, 1981). Although at the beginning pheromones were assumed to be unique substances, now it is widely accepted that they are

*Correspondence: Jean-Christophe Sandoz, Research Center for Animal Cognition, CNRS - University Paul Sabatier, 118 route de Narbonne, 31062 Toulouse cedex 9, France.e-mail: sandoz@cict.fr

Received: 24 October 2007; paper pending published: 14 November 2007; accepted: 30 November 2007; published online: 31 December 2007.

Citation: Front. Behav. Neurosci. (2007) 1: 5. doi: 10.3389/neuro.08.005.2007

Copyright $\odot 2007$ Jean-Christophe Sandoz, Nina Deisig, Maria Gabriela de Brito Sanchez and Martin Giurfa. This is an open-access article subject to an exclusive license agreement between the authors and the Frontiers Research Foundation, which permits unrestricted use, distribution, and reproduction in any medium, provided the original authors and source are credited. mainly blends of compounds so that variation in the ratios of components may define signals characteristic to different species (Mustaparta, 1996). This point is extremely important, as it provides concentration invariance to the signal, because if the relevant biological signal is a ratio between the concentrations of the different compounds, it can be decoded independently of absolute molecule numbers (Galizia, 2008).

Although pheromones are known throughout the animal kingdom, most of our knowledge on these substances was derived from research on insects. Besides the fundamental aspects of pheromone research, some of which are reviewed in this chapter in the case of the honeybee Apis mellifera, pheromones have attracted much attention due to their applied value. Indeed, pheromones are now used as control tools to fight against insect pests. They do not damage other animals, nor do they pose health risks to Humans. Pheromones can be used to lure the pests into traps, reducing the amount of insecticide applied on cultures (El-Sayed et al., 2006; Jutsum and Gordon, 1989). Besides, pest control can also be achieved by applying compounds that interfere with pheromone detection (Plettner, 2002).

Insect pheromones are secreted by exocrine glands and are transmitted to members of the species usually in vapor form and detected by the olfactory system. In some cases, pheromones are non-volatile molecules that are detected by the insects' gustatory system, as for instance cuticular hydrocarbons in Drosophila (Ferveur, 2005; Lacaille et al., 2007). In some species, like the silk moth Bombyx mori, only a few molecules of the volatile sex pheromone are necessary to produce an orientation response of the male toward the emitting female (Kaissling, 1987). This low amount of substance can be detected over long distance ranges so that the active 'air space' of a female (i.e., the range in which its pheromone will be an effective sex signal) can be several kilometers long and over hundred meters in diameter (Wilson, 1970). Any male entering this space, which adopts usually the form of an odor plume at whose base is the female, will fly through negative anemotaxis toward the odorant source in a typical zig-zag flight that involves turning commands 
triggered when the insect loses the plume (Olberg, 1983). This example emphasizes the extraordinary sensitivity of the neural olfactory system of insects for detecting pheromones, and the specificity of the behaviors triggered by these pheromones. One essential question in sensory neuroscience is to understand how such sensitivity and specificity can take place in the animal brain, and how the neural representation of such pheromones gives rise to such specific behaviors. As we will see, among insects, honeybees represent optimal models for such a quest, as the wealth of different pheromones and respective behaviors they support is unparalleled in the literature (Free, 1987).

\section{PHEROMONE COMMUNICATION IN A MODEL INSECT, THE HONEYBEE} APIS MELLIFERA

Honeybees are well known for their 'dance language', a stereotyped behavior that is used by returning foragers to recruit other foragers to food, water, and nest cavities (von Frisch, 1967). Such fascinating behavior, even in its highest complexity, constitutes only a small fraction of the communication systems that operate within a functioning colony, the other communication channels being mainly mediated by pheromones. As many other social insects, honeybees employ a very rich repertoire of pheromones to ensure intraspecific communication in many behavioral contexts (Free, 1987). The social organization of a honeybee colony is strongly determined by chemical signals that are actively produced and transmitted by the queen, the adult workers at various tasks and life stages, the brood and possibly drones.

The number of identified pheromonal compounds used by honeybees is too important to be fully listed here, so we will limit our survey to those pheromones that in each caste are best known and most studied because of their fundamental biological functions. It must be noted that such a rich pheromone repertoire, as already identified in the honeybee, may not be reserved to this particular insect species, but may reflect extensive investigations performed in this animal model, probably stimulated by the beneficial nature of this insect pollinator, and its inherent interest due to its social and cognitive complexity (Giurfa, 2007). Indeed, ants, wasps, termites and other social bees are also thought to possess complex pheromonal communication (van der Meer et al., 1998). However, pheromones in these species are less well characterized, and neurophysiological investigations of pheromone processing are still sparse.

Queen pheromones. The complex social organization of a hive depends on how the queen controls its environment. The queen, the only fertile female in the colony, must indeed communicate her presence and manifest her influence by means of a mixture of substances released mainly by her mandibular glands. This queen mandibular pheromone (QMP) reinforces social cohesion and has a releaser effect because it has an immediate effect on the behavior of the receiver bees, attracting and enticing them to lick and antennate the queen. It also has a priming effect, because, in the long-term, it changes the physiology of the receiver worker bees, inhibiting the development of their ovaries (Hoover et al., 2003). The priming effect of QMP is thought to rely on changes in the expression of many genes in workers, with a trend toward overexpression of nurse-related genes and repression of forager-related genes (Grozinger et al., 2003). Additionally, QMP was also recently shown to suppress the capacity of young bees to learn aversive experiences leaving appetitive ones intact (Vergoz et al., 2007). This effect has been interpreted as a way to tighten the bonds of young bees to their queen (Galizia, 2008).

QMP was originally considered to be a unique substance, 9-0xo(E)-2-decenoic acid (9-ODA) (Barbier and Lederer, 1960; Butler et al., 1961), but later studies revealed that other components integrate the pheromone. Addition of the two enantiomers of 9-ODA's biosynthetic precursor, (R)- and (S)-9-hydroxy-(E)-2-decenoic acid (9-HDA), failed to constitute an attractive blend for workers, although (R)-9-HDA is involved in the swarm-settling queen signal (Slessor et al., 1988). Two further components, methyl $p$-hydroxybenzoate (HOB) and 4-hydroxy3-methoxyphenylethanol (HVA), were finally recognized and formulated with the decenoic acids to provide a source nearly as attractive as an equivalent extract from the mandibular glands in which the five compounds are produced (Slessor et al., 1988).

More recently, novel components were extracted from several glandular sources, which act in synergy with the former ones to elicit full retinue behavior: methyl oleate, coniferyl alcohol, hexadecane-1-ol and linolenic acid (Keeling et al., 2003). From these compounds, only coniferyl alcohol is found in the mandibular glands. The combination of these four compounds and the five QMP compounds is called the Queen Retinue Pheromone (QRP). These nine compounds are important for the retinue attraction of worker bees around their queen. The queen pheromone is therefore, like other bee pheromones a complex blend which is most effective when all components are present in appropriate ratios in the blend.

Pheromones produced by the queens also play a crucial role for in-flight mating, being attractive to drones and helping them to find and follow virgin queens. Only the component 9-0DA has been demonstrated as clearly attractive to drones in experimental assays (Free, 1987). The role of other components like 9-HDA is controversial, and some may play a facilitating role when present in a blend with 9-ODA (Butler and Fairey, 1964; Blum et al., 1971; Boch et al., 1975; Brockmann et al., 2006).

Worker pheromones. Workers have to perform different tasks depending on their age. Bees of intermediate age are usually allocated to guarding and defense tasks at the hive entrance. Not surprisingly, therefore, worker bees present several alarm pheromones, which are released when confronting potential noxious stimuli or enemies (Breed et al., 2004). The main alarm pheromone is released by the Koschevnikov gland, which is situated near the sting shaft and consists of more than 40 highly volatile chemical compounds, including isopentyl acetate, (Z)-11-eicosenol, butyl acetate, 1-hexanol, 1-butanol, 1-octanol, hexyl acetate, octyl acetate, and 2-nonanol (Boch et al., 1962; Collins and Blum, 1982, 1983; Pickett et al., 1982). Release of this pheromone causes the other bees to sting or attack.

Another important alarm pheromone, 2-heptanone, is released by the mandibular glands (Shearer and Boch, 1965) and exerts a repellent action on potential intruders and robbers from other hives. Additionally, it has been suggested that it can be used by foragers, which are usually bees of older age, to mark recently depleted flowers whose immediate revisit has to be avoided (Giurfa and Núñez, 1992).

Other pheromones are used by workers to elicit attraction and recruit other workers to attractive places. This is the case of the pheromone of the Nasanov gland (Free, 1987; Winston, 1987), which is released from a gland situated on the dorsal surface of the $7^{\text {th }}$ abdominal tergum. This pheromone is a complex blend in which geraniol, nerol, $(\mathrm{E}, \mathrm{E})$-farnesol, (E)-and (Z)-citral and geranic and nerolic acid are the principal components (Pickett et al., 1980). The Nasanov pheromone is released in a variety of circumstances in which it releases attraction and aggregation of receiver workers. It is used to mark the entrance of the nest, to mark profitable food and water sources and for attracting purposes in a swarming context (i.e., to recruit nestmates to a new nesting cavity).

Novel pheromonal compounds are regularly discovered in honeybees. Very recently, a possible waggle-dance pheromone was described (Thom et al., 2007). As mentioned above, honey bee foragers execute waggle dances in the colony to recruit other bees to profitable food sources, thereby indicating the direction and distance of the food source (von Frisch, 1967). During the waggle-dance, foragers release four compounds related to cuticular hydrocarbons, two alkanes, tricosane and pentacosane, and two alkenes, Z-(9)-tricosene and Z-(9)-pentacosene. These substances, when injected into a hive, significantly increase the number of foragers leaving the hive, suggesting that they may play a pheromonal role in worker recruitment. Interestingly, these compounds were already well known for being present on honeybee cuticular profiles (Blomquist et al., 1980) and to be detected and perceived by honeybees (Châline et al., 2005; Getz and Smith, 1987). However, their possible pheromonal nature was unknown. 
Drone pheromones. Drones seem to have pheromones that attract other flying drones to promote drone aggregations at sites suitable for mating with virgin queens. Such substances may help establish aerial congregation sites (Free, 1987). Male aggregation pheromones have been identified from the mandibular gland of some hymenopteran species (Ayasse et al., 2001), and Lensky et al. (1985) suggested that a similar gland exists in drone honeybees. However, in honeybees, such a possibility has not been demonstrated yet.

Brood pheromones. Other pheromones exist such as the brood pheromone, a mixture of ethyl and methyl esters of the common fatty acids palmitic, linoleic, linolenic, stearic, and oleic acids from larvae. Four of these methyl esters were originally considered to be a signal from larvae to adults to cap the brood cells prior to their pupation. The methyl esters of palmitic and oleic acid were most effective in recruiting workers to this role. In addition, differences in the proportions of esters provide a chemical signature of larval age. A component of this blend, methyl linolenate results in enhanced provisioning of new queen cells with more royal jelly, facilitating the healthy development of new queen larvae (Le Conte et al., 1995). Two of the brood esters with demonstrated releaser effects, ethyl palmitate and methyl linolenate, also have priming effects partially inhibiting the ovarian development of worker bees, at least in an experimental situation in which the workers are isolated from a queen and brood (Arnold et al., 1994; Mohammedi et al., 1998).

In this article, we will ask how such a wealth of pheromonal signals is processed in the honeybee brain. How different is pheromonal processing from the processing of environmental odors? And within pheromones, does the kind of processing differ depending on the nature and/or biological value of the pheromone considered? Honeybees present both sexual and social pheromones. Do both types follow the same processing strategy, given that they are subjected to very different natural constraints relating to mate finding outside the hive on the one hand, and social organization within the hive on the other? In bees, the same compounds, for instance the QMP components, can have both sexual and social qualities, depending on the receiver being a male or a worker. Will the processing of this compound be different in these two castes?

\section{CODING PRINCIPLES IN PHEROMONE AND GENERAL ODOR PROCESSING}

Having mentioned some examples of honeybee pheromones that underline the richness and complexity of the chemical repertoire used by this insect to mediate intraspecific communication, we will focus on the question of neural pheromonal processing. We will analyze current knowledge of how pheromonal signals of different nature are processed in the olfactory nervous system of the honeybee, from the periphery to the more central levels. In that sense, it is important to mention the two main hypotheses proposed for olfactory coding that have profoundly impregnated studies of pheromone processing until now, the labeled-line and the across-fiber pattern hypotheses (Figure 1). Both hypotheses attempt to explain olfactory coding in terms of activity in populations of neurons. These principles originate from early electrophysiological work in moths which found a compelling functional dichotomy of ORNs (Boeckh et al., 1965): while some ORNs responded to a wide range of different odors, some were found to be highly specific. This last type concerned ORNs involved in sexual communication. According to the labeled-line theory, each receptor is highly specific, responds to one stimulus or a very limited range of stimuli and sends a direct 'line' to the central nervous system to communicate information about this (or those) particular odorant(s). According to the across-fiber pattern theory, each receptor is less specific and responds to a wider range of stimuli; the entire population of odorant-responsive neurons participates in the odor code

Labeled-line processing has the advantage of providing very precise knowledge about a limited number of odorants because each separate channel is dedicated to one (or a few) odorant(s). On the other hand, it
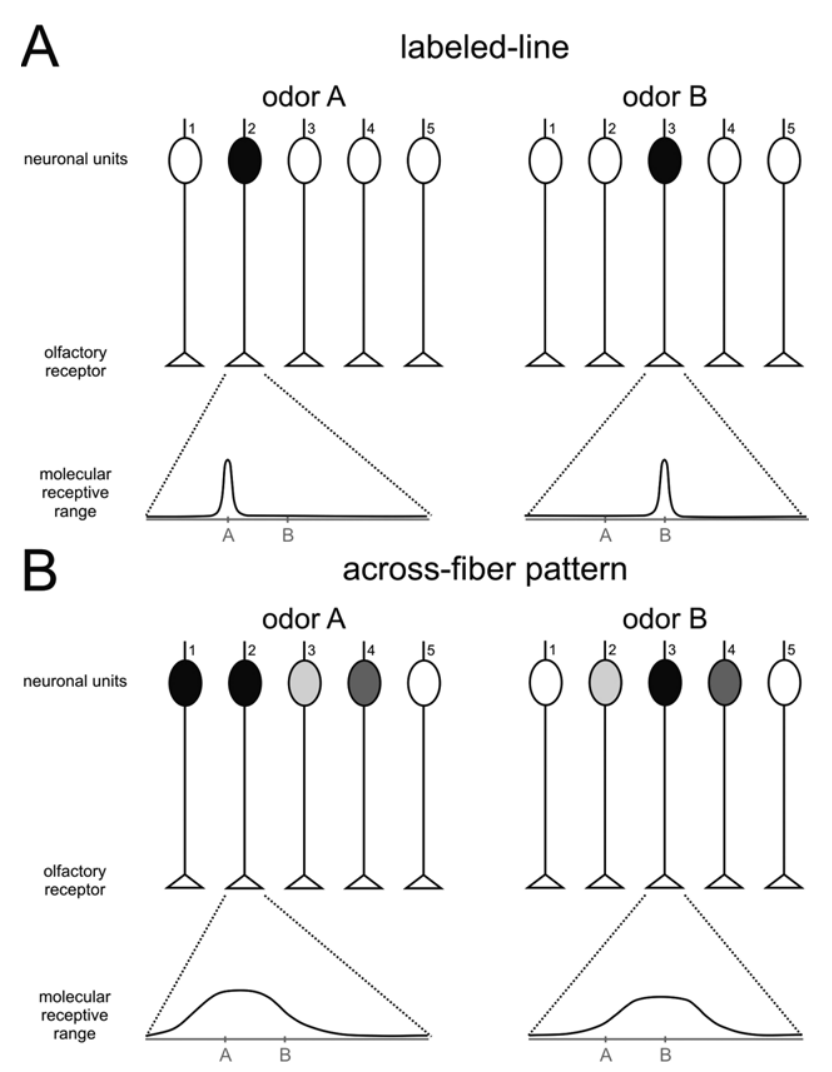

Figure 1. Schematic representation of two theories of odor processing. A simplified olfactory system (without lateral connections) is presented, with five different receptor neurons. Below each graph, the molecular receptive range of chosen receptor neurons is represented, according to a putative chemical dimension along which chemically similar odorants would be placed near each other on the scale. An example of such a dimension would be the number of carbon atoms in an aliphatic chain. (A) Labeled-line: each receptor has a narrow molecular receptive range, i.e., it is activated by a single (or very few) odorant(s). Two different odors, $A$ and $B$, are each detected by only one receptor, which activates only one neuronal unit. Differentiation between $A$ and $B$ does not need further processing, but only five different odorants can be thus coded. (B) Across-fiber pattern: each receptor has a broad molecular receptive range, i.e., it can be activated by a range of different odors. The five different receptors have different - but broad - receptive ranges. In our example, odor $A$ will activate several neuronal units, although with different intensities depending on the receptor. Receptor 2 will be highly activated by odor $A$, but only slightly by odor $B$. Receptor 3 shows the opposite response profile. Among the other receptors, some will be equally activated by the two odors (receptor 4), others will show a contrasted response (i.e., responding to $A$ but not to $B$; receptor 1), while others will not be activated at all by either odor (receptor 5). This system allows the fine coding of many odors, but differentiation among odors needs additional downstream processing as the representation of each odor is contained in the combination of activations of the different neuronal units.

cannot code, given the natural constraints of neural systems (e.g., number of neurons), all possible odorants in the environment. Labeled-line processing is therefore a good system for detecting and recognizing a few stimuli with a crucial biological value for the animal (e.g., pheromones), but not for general odor coding. Conversely, the combinatorial across-fiber processing can code a much higher number of odorants with the same number of neurons, but may be much less specific in its ability to detect a particular odorant, especially at low concentration.

We believe that the honeybee, which shows a remarkable number of pheromones, each with various components, represents a conceptual challenge for such a simple dichotomous model of pheromone vs. general odor 
processing. Are all the honeybee pheromones represented by labeled-lines to the central nervous system? Do such labeled-lines only exist in the drone or do they also exist in workers? In presenting the different physiological steps of pheromone processing in the honeybee, we will discuss in light of available data whether pheromone processing follows labeled-lines or across-fiber patterns.

\section{BASIC ORGANIZATION OF THE HONEYBEE OLFACTORY SYSTEM}

Considerable previous work in the honeybee has provided a thorough description of its olfactory circuits, making of this insect a choice model for studying the neural basis of pheromone detection and processing (e.g., Abel et al., 2001; Gronenberg, 2001; Kirschner et al., 2006; Mobbs, 1982; Müller et al., 2002). We describe here the anatomical organization
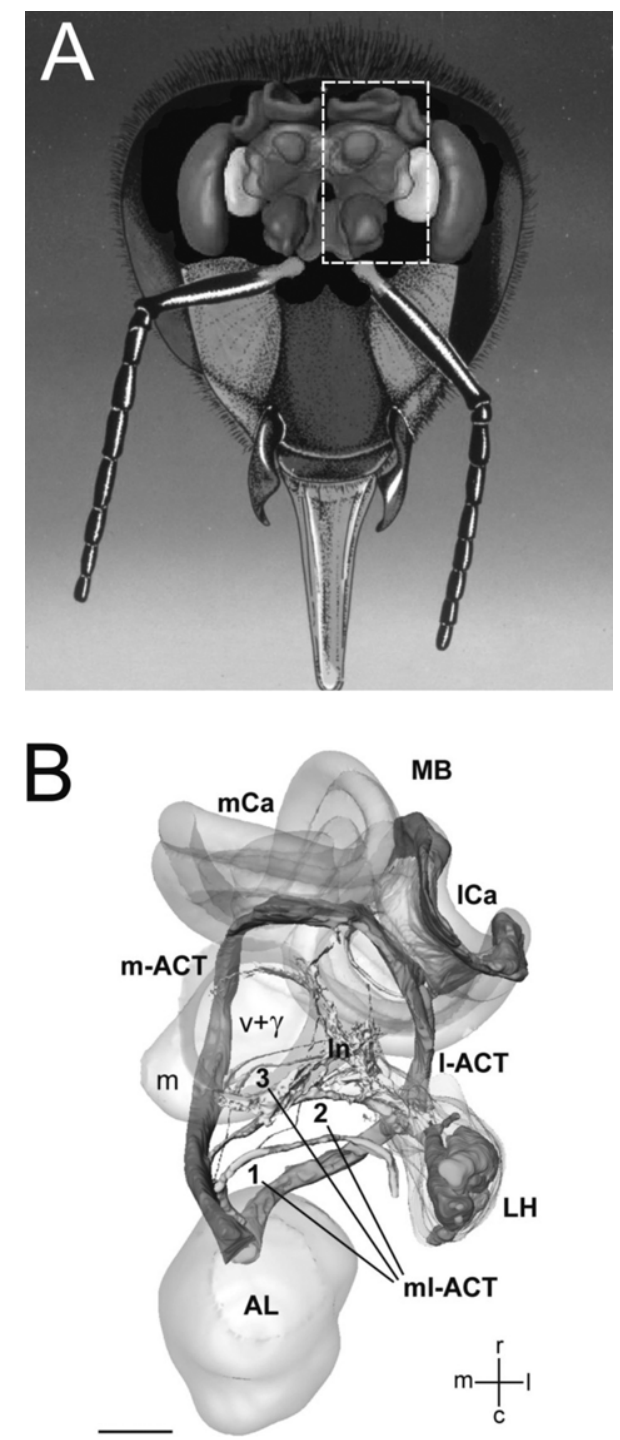

Figure 2. The basic organization of the honeybee olfactory system. (A) Frontal view of the brain with the main olfactory centers. (B) Threedimensional reconstruction of the olfactory circuit based on confocal microscopy (corresponding to the bees' left half-brain, see broken line in (A); AL: antennal lobe; LH: lateral horn; MB: mushroom body; m-ACT: medial antenno-cerebral tract; I-ACT: lateral antenno-cerebral tract; mCa: medial calyx; ICa: lateral calyx. The three ml-ACTs (mediolateral antenno-cerebral tracts) 1-3 branch off the $m$-ACT sequentially and innervate the lateral protocerebral lobe to form the lateral network (In) that spans from the vertical lobe $(v+\gamma)$ to the LH. Scale bar: $100 \mu \mathrm{m}$ (Figure 3B adapted from Kirschner et al., 2006 by kind courtesy of Wolfgang Rössler). of the olfactory system of the honeybee (Figure 2). We focus on honeybee workers as the basic construction plan relative to which specificities in pheromone processing resulting from caste and/or sex will be discussed.

Peripheral odor detection starts at the level of olfactory receptor neurons (ORNs), which are located within cuticular structures (cavities or evaginations) on the antennae, called sensillae. Odorant molecules reach the neurons, either by diffusing through a receptor hemolymph located in the sensillum cavity and surrounding the ORNs, or, since they are mostly lipophilic, need to be carried by amphiphilic odorant-binding proteins (OBP) that bring them through the receptor hemolymph to the ORN membrane surface. In the honeybee, relatively few genes coding for OPBs have been found in the genome, so that the relative importance of this last phenomenon in this species is still unclear (Forêt and Maleska, 2006). The odorant molecule will then bind to a molecular olfactory receptor (Or) in the membrane providing that structural complementarity exists between odorant molecule and Or structure. Ors are seven-transmembrane domain proteins, coupled to $\mathrm{G}$ proteins that will activate cellular transduction cascades implicating the production of cAMP, leading eventually to depolarization and action potentials.

When ORNs are thus activated by the appropriate ligand molecule, their axon convey the olfactory message via the antennal nerve to the antennal lobe $(A L)$, the primary olfactory center in the insect brain. The antennal nerve (AN) splits into six sensory tracts upon entrance to the $A L$. Four of these tracts (T1-T4) innervate distinct areas in the $A L$. The two remaining tracts ( $T 5, T 6)$ bypass the $A L$ and project to the antennal mechanosensory center in the deutocerebrum (called the dorsal lobe, DL), the suboesophageal ganglion (SOG), and the caudal protocerebrum. The $A L$ is compartmentalized in spheroidal neuropile units called glomeruli. Glomeruli are the anatomical and functional units of the $\mathrm{AL}$ and constitute sites of synaptic interaction between different neuron types. Axons of ORNs expressing the same odorant receptor or with similar odor specificities converge onto the same glomerulus and contact local inhibitory interneurons connecting different glomeruli and projection neurons that relay the olfactory message processed at the level of the $\mathrm{AL}$ to higher-order centers such as the lateral horn $(\mathrm{LH})$ and the mushroom bodies (MBs). Local interneurons are thought to carry out the first processing of olfactory information through both global inhibition for gain control and asymmetrical lateral inhibition between glomeruli for refining odor representation and allowing better discrimination among olfactory representations (Sachse and Galizia, 2002).

After the $\mathrm{AL}$, olfactory information takes several routes to MBs and $\mathrm{LH}$. Five antenno-cerebral tracts (ACTs) of projection neurons thus leave the honeybee AL (Abel et al., 2001; Mobbs, 1982). The medial and lateral output tracts ( $m$ - and I-ACT) are made of axons of uniglomerular projection neurons (uPNs) that convey information both to the MBs and LH (Abel et al., 2001; Bicker et al., 1993; Brandt et al., 2005; Müller et al., 2002). Interestingly, glomeruli transmit their information to higher centers via either one of these two main tracts, but not both (Abel et al., 2001; Kirschner et al., 2006). Apart from these two tracts, three smaller mediolateral tracts (ml-ACTs) project only to the LH and surrounding protocerebral areas and contain mainly axons of multiglomerular projection neurons (mPNs) (Fonta et al., 1993).

Axonal terminals of uPNs are relayed to densely packed MB-intrinsic neurons, the Kenyon cells (KCs; 170000 per MB). The MBs present cupshaped regions termed calyces, which receive input from olfactory and visual pathways, and also probably from mechanosensory and gustatory pathways (Strausfeld, 2002). MB calyces are anatomically and functionally subdivided into the basal ring, collar, and lip (Gronenberg, 2001; Mobbs, 1982; Strausfeld, 2002). The lip region and the inner half of the basal ring receive olfactory input, whereas the collar and outer half of the basal ring receive visual input (Gronenberg, 2001). Further segregation according to the origin of the uPNs (medial- or lateral-ACT neurons) has been recently shown using double staining: PNs of the $\mathrm{m}$-ACT innervate the peripheral part of the olfactory basal-ring region, whereas PNs belonging to the I-ACT innervate the central part of the basal ring (Kirschner et al., 2006). 
The second major target area of both the m- and I-ACT uPNs is the $\mathrm{LH}$. In addition to the uPN innervation, the $\mathrm{LH}$ receives input from mPNs via the ml-ACTs (Fonta et al., 1993). Similarly to the olfactory input of the MB calyx, the LH shows a PN tract-specific compartmentalization, with at least 4 subcompartments: one receives exclusively projections of $\mathrm{m}$-ACT uPNs, while others receive mixed input from $\mathrm{m}$ - and I-ACT PNs, from I-ACT and ml-ACT PNs, or from the latter type alone (Kirschner et al., 2006). While the function of the LH is still unclear (see below), it is known that the MBs are involved in further processing of olfactory signals and in olfactory learning and memory, as well as the combination of olfactory information with other sensory modalities (Giurfa, 2003, 2007).

Although the anatomical description of central projections within olfactory circuits is very good, functional knowledge of these pathways, in particular concerning the possible segregation between pheromonal and non-pheromonal processing is still in its infant stage. The clearly structured and segregated organization of the bee olfactory system, with several parallel olfactory pathways from the $A L$ to $M B s$ and $L H$, could support the idea of a labeled-line organization, with pheromonal processing following specific pathways, different from those used to code nonpheromonal odorants. In the next sections, we will focus on functional analyses which support or challenge this hypothesis and on olfactory specializations arising from differences in caste or sex.

\section{PHEROMONAL PROCESSING AT THE PERIPHERY: OLFACTORY SENSILLAE AND RECEPTORS \\ The sensillae}

The antennae of the honeybee are the organs on which sensillae containing ORNs are located. Different types of sensillae have been traditionally distinguished based on their particular morphology: sensillae placodea, ampulacea, coeloconica, basiconica, campaniforme and trichodea. From all these types, sensillae placodea, which appear in the form of poreplates, are the main olfactory antennal structures in the honeybee (Esslen and Kaissling, 1976). Each sensillum placodeum consists of a $9 \times 6 \mu \mathrm{m}$ thin oval cuticular plate with numerous minute pores and is innervated by 5-35 neurons (Esslen and Kaissling, 1976; Kelber et al., 2006). There is a remarkable dimorphism between workers and drones with respect to the relative number of sensillae of each type and to the total number of sensory cells. Workers have far more of sensillae trichodea while drones lack sensillae basiconica and have far more sensillae placodea than the worker. The flagellum surface of the drone is twice as large as that of the worker and has 7 times as many sensilla placodea $(\sim 18,000$ compared with $\sim 2,600)$ (Brockmann and Brückner, 2001; Esslen and Kaissling, 1976). The worker flagellum has a poreplate-free zone on the side facing the head which is densely packed with non-innervated hairs. In the corresponding zone, the drone has poreplates, although with a lower density than elsewhere on its antennal flagellum (Figure 3). This difference in sensory equipment on the antennae of workers and drones translates into high differences in the number of sensory cells: $\sim 65,000$ in the worker for $\sim 340,000$ in the drone (Esslen and Kaissling, 1976).

Electrophysiological recordings revealed that the receptor neurons of the sensillae placodea respond to a variety of plant and flower odorants as well as to components of the honeybee pheromones (Esslen and Kaissling, 1976; Lacher and Schneider, 1963; Vareschi, 1971). In particular, olfactory neurons within sensillae placodea of drones respond to 9-ODA, the main component of QMP (see below).

\section{The receptors}

As mentioned above, an ORN presents molecular olfactory receptors (Ors) in its membrane, which allow binding of odorant molecules. In insects, the functional receptor is a heteromeric complex of a conventional odor ligand-binding receptor (Or) with a broadly expressed co-receptor (0r83b in Drosophila, Benton et al., 2006). One kind of odor ligand-biding Or

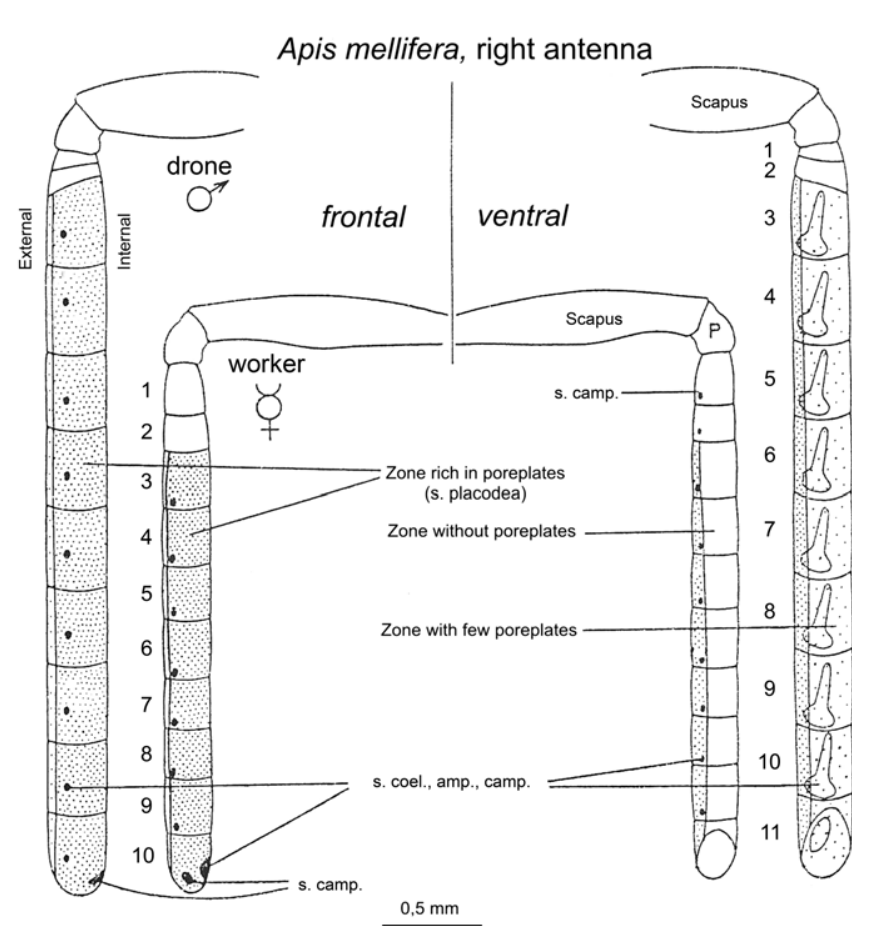

Figure 3. Schematic representation of the worker $(q)$ and drone $(\widetilde{c})$ right antenna in frontal (left) and ventral (right) view. The highly dotted, less dotted and empty segments correspond to segments rich, moderately rich and deprived of sensillae placodea (poreplates), respectively. Adapted from Esslen and Kaissling (1976).

is generally present per ORN (Dahanukar et al., 2005), which confers specific odor responses to the neuron. Taking advantage of the recent availability of the honeybee genome (The Honeybee Genome Sequencing Consortium, 2006), Robertson and Wanner (2006) showed that honeybees present a remarkable expansion of the insect odorant receptor (Or) family relative to the repertoires of the flies Drosophila melanogaster and mosquitoes Anopheles gambiae, which have 62 and 79 0rs, respectively. Indeed, a total of 170 Or genes were annotated in the bee, of which seven are pseudogenes. This number coincides with the number of glomeruli present in the antennal lobe ( 165 , Galizia et al., 1999a), thus supporting the one-receptor/one-neuron/one-glomerulus relationship (Dahanukar et al., 2005).

Which molecular specificity do these or genes present? Although neurogenetic studies performed in the fruit fly Drosophila melanogaster have shown that an Or confers the odor response spectrum to its olfactory neuron and other response properties such as the spontaneous firing rate, the temporal dynamic of the response and whether the response is excitatory or inhibitory (Hallem et al., 2004), less is known about Or specificity in honeybees. An exception is the case of the Or for the queen mandibular pheromone component 9-0DA, which has recently been identified (Wanner et al., 2007). Wanner et al. (2007) identified four candidate sex pheromone Ors from the honey bee genome based on their biased expression in drone antennae relative to worker antennae. This number coincides with the number of macroglomeruli in the drone antennal lobe (Arnold et al., 1985; Brockmann and Brückner, 2001; see below). In other insect models, macroglomeruli respond specifically to the female-produced sex pheromones and the number of macroglomeruli generally corresponds to the number of sex pheromone components. The pheromone responsiveness of these four Ors preferentially expressed in the drone antennae was studied by expressing them in Xenopus oocytes, which allowed characterizing electrophysiologically their molecular specificity. One of the Ors (called AmOr11) specifically responded to 9-ODA 
and not to any of the other queen retinue pheromone (QRP) components, worker pheromones or floral odors. Interestingly, the other three Ors preferentially expressed in the drone antennae could not be linked to other queen pheromone components.

The existence of an Or specifically tuned to 9-ODA is coincident with previous suggestions on Or olfactory tuning based on the electroantennogram (EAG) technique, in which a global neuronal response to odorants is recorded at the level of the whole antenna. By testing queen pheromone components, Brockmann et al. (1998) found that EAG responses of worker and drone antennae differ so that workers exhibit a generalized response to numerous odor compounds, both pheromonal and non-pheromonal, while drones have an EAG profile more specifically tuned to 9-ODA. Another study performing patch-clamp recordings of ORNs in primary culture showed a much higher probability of drone ORNs responding to QMP (and to 9-ODA and 9-HDA) relative to workers' ORNs which generally responded to mixtures of general odors or of social pheromones (Laurent et al., 2002). This difference indicates that already at the peripheral level, dramatic differences exist between drones and workers in terms of their investment in the processing of different pheromonal and non-pheromonal odorants. While males exhibit a clear olfactory specialization for the sexual pheromone 9-ODA, consistent with their exclusive reproductive role in the hive, worker bees show a broader response range at the periphery, consistent with their use of these different signals in different behavioral contexts.

So far no other receptor genes have been found for other queen pheromone components. This result is surprising because behavioral experiments have suggested the effect of other QMP components on male attractiveness. For instance, Brockmann et al. (2006) tested the attractiveness of 9-ODA compared to mixtures of 9-ODA with three other most abundant components in virgin queen mandibular gland secretions: 9-HDA, HOB, and (2E)-10-hydroxydecenoic acid (10-HDA). No differences in the number of drones attracted over a distance to a rotating dummy baited with 9-ODA or the respective mixtures were found. However, adding 9-HDA and 10-HDA, or 9-HDA, 10-HDA, and HOB to 9-ODA increased the number of drones actually making contact with the baited dummy. It was therefore suggested that 9-HDA and 10-HDA may be additional components of the sex pheromone blend of $A$. mellifera, at least for short range attraction. An exhaustive functional screening of drone Ors should therefore yield evidence for the existence of other Ors tuned to these additional queen pheromone components. A clear dimorphism between workers and drones might exist with respect to the presence of these receptors. Alternatively, new queen pheromone components may exist which have not yet been identified (see "Processing at the antennal lobe" section).

\section{PHEROMONAL PROCESSING \\ AT THE CENTRAL LEVEL \\ Processing at the antennal lobe}

At the central level, there is also a clear sexual dimorphism, in particular at the level of the first olfactory center, the antennal lobe (AL). Most anatomical descriptions of the AL have been performed on workers (e.g., Flanagan and Mercer, 1989; Galizia et al., 1999a; Pareto, 1972), whilst data on drones and queens are rather scarce (Arnold et al., 1985, 1988). Likewise, most electro- and opto-physiological studies of olfactory processing have been performed in the worker (Abel et al., 2001; Galizia et al., 1999b; Joerges et al., 1997; Müller et al., 2002). We present below, separately for each caste, the available data on representation of pheromonal and general odors in the antennal lobe.

In workers, the AL consists of $\sim 165$ glomeruli (Figure 4). It is in the worker honey bee that the first successful calcium imaging recordings revealed the neural representation of odors as a glomerular activity pattern in the antennal lobe (Joerges et al., 1997).The basic principle of this recording technique resides in visualizing with fluorescent dyes the increase of intracellular calcium (coming from the extracellular medium and/or released from intracellular stores) following neuronal excitation. Such dyes bind to free calcium, thereby changing their fluorescence excitation or emission properties. Using a dedicated setup with a highly sensitive CCD camera and an epifluorescence microscope, it is possible to monitor calcium concentration changes from brain structures throughout odor stimulations (Galizia and Vetter, 2004; Galizia et al., 1997). To record neural activity in this way, bees are fixed in a recording chamber, and the head capsule is carefully opened. Membranes and trachea covering the brain are removed, and a calcium-sensitive fluorescent dye (for instance, Calcium Green $2 \mathrm{AM}$ ) is bath-applied onto the brain. After about $1 \mathrm{~h}$ staining, the brain is rinsed with saline solution and the bee is placed under an upright fluorescence microscope in front of an odor stimulation device. Another staining technique allows the specific recording of projection neurons, using retrograde staining of these neurons with dextran-coupled dyes (Sachse and Galizia, 2002). In the AL, odors were found to elicit combinatorial activity patterns across glomeruli (Joerges et al., 1997; see Figure 5A) and odor quality is represented by a specific distributed code, conserved between individuals (Galizia et al., 1999b; Sachse et al., 1999). Olfactory mixtures, which are particularly important in the context of foraging on natural floral sources, are represented by glomerular patterns that correspond to rather linear computations from the patterns of their components (Deisig et al., 2006). From all this data, it is clear that general odorant coding in the worker AL corresponds to an across-fiber pattern, each glomerulus showing a rather broad molecular
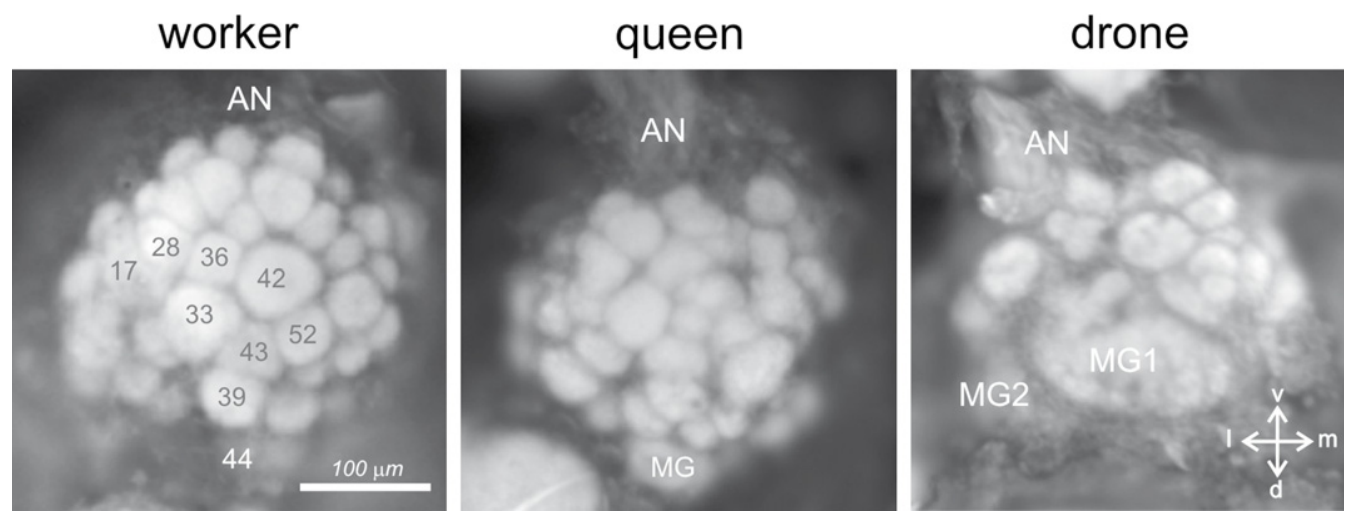

Figure 4. Anatomy of the antennal lobe in the three honeybee castes. Anatomical staining (4\% neutral red) of the left antennal lobes of a worker (left), a queen (middle) and a drone (right). The lobes are shown in frontal view, in the position in which they can be accessed during calcium imaging recordings. About 1/4 of the antennal lobe is thus accessible (30-40 glomeruli in workers). AN: antennal nerve; MG: macroglomerulus; v: ventral; l: lateral; m: medial; d: dorsal. Numbers in workers refer to identified glomeruli of the T1 ORN tract. 


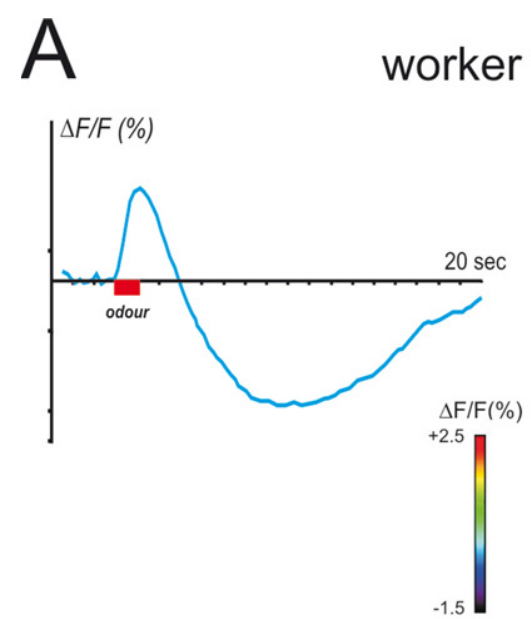

B

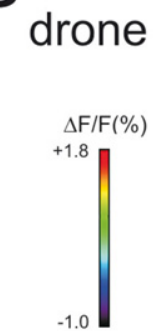

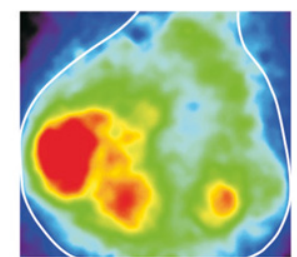

2-octanol

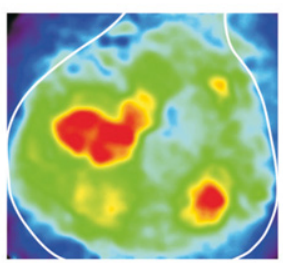

1-hexanol

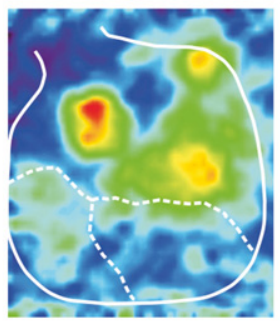

orange oil

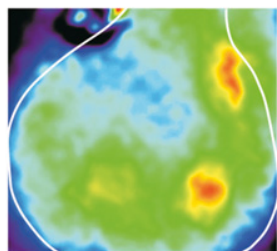

IPA

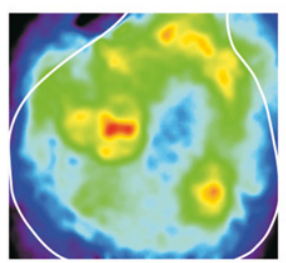

citral

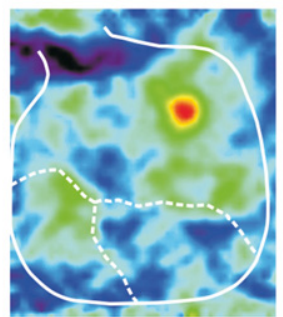

HVA

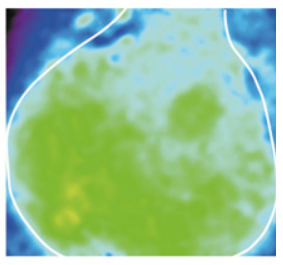

HVA

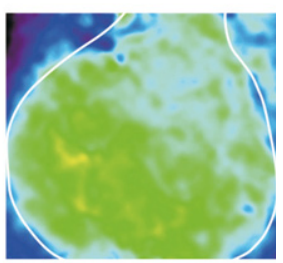

9-ODA

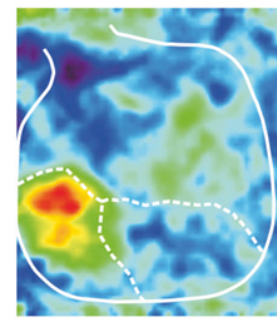

9-ODA

Figure 5. Physiological responses of the antennal lobe in workers and drones. (A) Calcium imaging recording (using bath-applied Calcium Green 2AM) in a worker bee. Upper left: upon odor delivery, a biphasic fluorescence signal is observed in active glomeruli, with a first fast positive component (max after $\sim 1$ second), followed by a slow - highly spatially correlated - negative component (minimum after 8-10 seconds). Right: Odor activity maps, showing for each pixel in a false-color code the amplitude of the biphasic signal. General odors (1-hexanol and 2-octanol) and social pheromone (isopentyl acetate, IPA and citral) elicit combinatorial activity in the imaged glomeruli. Note that the glomeruli activated by the pheromones can be active in response to general odors and vice-versa. By contrast, no clear signals appeared with components of the queen mandibular pheromone (here 9-ODA and HVA). We believe the glomeruli responsible for processing of these signals are in other - yet unimaged - parts of the antennal lobe. (B) Calcium imaging recordings (using bath-applied Calcium Green 2AM) of antennal Iobe activity in a drone bee. The odor activity maps are calculated as in (A). The position of the two accessible macroglomeruli is overlaid on the maps (white). General odors (here a complex blend, orange essential oil) and social pheromones (here geraniol) induce activity in ordinarysized glomeruli, i.e., on the medio-ventral side of the antennal lobe. Interestingly, the major component of the queen mandibular pheromone, 9-0DA, which is involved in the attraction of males toward queens during nuptial flight, is specifically detected by the most voluminous macroglomerulus of the drone antennal Iobe, MG2. By contrast, HVA, another QMP component whose role has only been proven in workers, induces activity in an ordinary-size glomerulus (for details, see Sandoz, 2006).

receptive range and odor quality being represented in the combination of activated glomeruli (Galizia et al., 1999b).

Moreover, activity patterns in the AL clearly correspond to a perceptual representation of odorants, since physiological similarity between activity patterns correlates well with perceptual similarity measured from bees' generalization performances after conditioning to a wide spectrum of selected odors (Guerrieri et al., 2005). In imaging studies (Galizia et al., 1999b; Sachse et al., 1999; our work), apart from floral odors, several pheromonal components were also presented to worker bees, such as worker-emitted (social) pheromones, like geraniol and citral (aggregation; see above), isopentyl acetate and 2-heptanone (alarm; see above), or components of the queen mandibular pheromone. The common picture emerging from these studies is that both floral odors and social pheromones induce clear responses in the workers' AL, each compound eliciting activity in a combination of glomeruli, irrespective of their social or floral nature (see Figure 5A). However, QMP presented either as a blend (Galizia et al., 1999b) or as its separate components (our recordings, see Figure $5 \mathrm{~A}$ ) induces very little activity in these glomeruli.

When comparing the signals corresponding to social pheromones and floral odors, visual observation does not allow isolating any glomerulus that could be specifically involved in pheromone processing. In particular, it was observed that the signal induced by 2-heptanone, a ketone with an aliphatic chain of 7 carbons that acts as an alarm pheromone (see above), elicits an activity pattern that appears halfway between those of 2-hexanone (6 carbons) and 2-octanone (8 carbons) (Sachse et al., 1999), two non-pheromonal molecules. Thus, at first glance, signals to 2-heptanone seem to belong to a continuum of increasing chain length within ketones. However, careful similarity measures performed by Sachse et al. (1999) taking into account the whole odor patterns clearly showed that the 2-heptanone signal has a particularity: whereas all the molecules tested in this study (belonging to functional groups like alcohols, aldehydes and ketones, with chain lengths between 5 and 10 carbons) showed a clear similarity relationship depending on chain length (longer chains supporting more similarity between odors from different functional groups), 2-heptanone showed a dramatic drop in similarity relative to odors of the same chain length (Sachse et al., 1999, see Figure $6 \mathrm{C}$ therein). In other words, the pattern of 2-heptanone was more distinct from those of other odors than could be predicted from the chainlength/similarity rule indicated above. What can be concluded from these observations? Social pheromones in the honeybee (but also in other Hymenoptera) are rather common molecules, which bees may certainly encounter in their natural environment, in particular as components of 
floral aromas (see Knudsen et al., 1993). It is therefore not astonishing that these molecules are detected by the general olfactory system and induce glomerular activity patterns in the same regions of the $\mathrm{AL}$ as floral odors. Pheromones could thus be detected by this part of the olfactory system of workers as a general odor because of their rather common chemical structure. Indeed, behavioral data indicate, that these social pheromones (citral, geraniol, isopentyl acetate, 2-heptanone) can be easily learned by bees in appetitive conditioning experiments (Getz and Smith, 1987; Sandoz et al., 2001; Smith, 1991). Even though learning takes place, social pheromones do not seem to be treated by bees like general odors. For instance, it was found that alarm pheromones (IPA and 2-heptanone) can produce very high generalization (i.e., conditioned responses to another odor than the trained one) to different odors after conditioning (Sandoz et al., 2001). Most puzzling, although these two molecules do not have a similar structure, very high generalization between them was observed, suggesting that when learning pheromones in an appetitive context, bees also associate their biological value (here a defense value) to the appetitive reward and use such information to generalize.

The fact that glomerular activity to the social pheromones is observed in one AL region ( $\mathrm{T} 1$ ) thought to be responsible for the coding of general odors does not preclude that other regions of the AL (belonging to ORN tracts $\mathrm{T} 2, \mathrm{~T} 3$ or T4) could be dedicated to the detection of these social odors as pheromones. Clues as to which AL region could be involved in social or queen pheromone processing are yet too scarce to allow making predictions. New physiological experiments should be performed, measuring responses from the other glomerular populations using optical imaging. Because of their position in the brain, glomeruli from the T2-T4 tracts are not easily accessible to conventional microscopy, and have mostly been ignored by imaging studies (Galizia and Menzel, 2001). The recent development of multi-photonic microscopy, which allows to image more deeply within brain structures with good spatial and temporal resolutions, could be one solution to this problem. Additionally, the electrophysiological study of individual neurons coupled to their precise labeling and glomerulus identification (Abel et al., 2001; Galizia and Kimmerle, 2004; Müller et al., 2002) should be systematically pursued, using a standardized odor list containing all the different classes of odorants.

In drones, tracts of olfactory receptor neurons are thicker but project into a smaller number of glomeruli than in workers (Arnold et al., 1985). Most of them $(\sim 103)$ correspond to glomeruli of a similar size to those of workers ('ordinary' glomeruli). However, the most dramatic difference between the drone and the worker $\mathrm{AL}$ is the presence in the drone of four hypertrophied glomeruli, the macroglomeruli (Arnold et al., 1985, see Figure 4). Their important volume and their anatomical similarity to the macroglomerular complexes found in males of several moth species (e.g., Kaissling, 1987), where they are involved in the detection and processing of female pheromone components, suggested that macroglomeruli in honeybee drones could play a similar role and serve the detection and processing of queen pheromonal components (Arnold et al., 1985; Masson and Mustaparta, 1990). Recently, we have used in vivo calcium imaging to study responses to pheromonal and general odors by the drone antennal lobe (Sandoz, 2006; Figure 5B). Two out of four macroglomeruli and about 20 ordinary glomeruli on the frontal surface of the antennal lobe, all belonging to the $\mathrm{T} 1$ tract of ORNs, were accessible to our recordings. We found that the macroglomerulus MG2, which is the most voluminous of the drone AL, responds specifically to the main queen pheromone component 9-0DA but not to other social and floral odors tested. This result therefore confirmed the hypothesis formulated by Arnold et al. (1985) and fits well with previous electrophysiological studies showing that an important part of the drone peripheral olfactory system is dedicated to the detection of 9-0DA (Brockmann et al., 1998; Kaissling and Renner, 1968; Skirkeviiene and Skirkeviius, 1994; Vareschi, 1971; Vetter and Visscher, 1997; see above). This result also coincides with molecular studies on antennal Ors in drones (Wanner et al., 2007; see above). In those studies, four Ors were found that were preferentially expressed in the antennae of drones but only one could be assigned to 9-0DA. Probably, ORNs expressing the 9-ODA-specific Or send their axon terminals directly to MG2. This would correspond to a labeling-line processing strategy rather than to an across-fiber pattern strategy.

Our calcium imaging studies did not detect any activity in the other accessible macroglomerulus, MG1 when drones were stimulated with the odors presented in our study (queen mandibular components, social pheromones, floral odors). We believe that MG1 may respond to other queen components that were not present in our samples. Note also that the molecular studies mentioned above (Wanner et al., 2007) could also not assign the other three Ors to other QMP components. In fact, until now, apart from 9-0DA, the search for queen pheromonal components has mainly focused on creating blends able to accurately reproduce workers' - but not drones' - behavior (Keeling et al., 2003; Slessor et al., 1988). Therefore, even if 9-0DA is clearly the main attractant for drones, the question of possible co-attractants is still mostly unsolved. Since the initial description of a queen mandibular extract able to reproduce the retinue behavior of worker bees (9-0DA, 9-HDA, HVA and HOB; Slessor et al., 1988), novel components have been found which act in synergy with the former ones: methyl oleate, coniferyl alcohol, hexadecane-1-ol and linolenic acid (Keeling et al., 2003). Such components should be tested in imaging conditions, as should complete queen extracts. In our work, 9-HDA failed to induce consistent signals. Moreover, responses to HVA and HOB occurred mainly in two ordinary glomeruli, which clearly responded to general odorants (Sandoz, 2006), suggesting that the responses obtained to HVA and $\mathrm{HOB}$ are due to their detection by the general olfactory system and not by a pheromonal subsystem. In fact, 9-HDA, HOB and HVA were isolated for their role on worker behavior, and may not have a pheromone value for drones in nature. So far, only one study found drone attraction to 9-HDA (Butler and Fairey, 1964) but two subsequent studies failed to reproduce this result (Blum et al., 1971; Boch et al., 1975). As mentioned above, though, 9-HDA could play a role as co-attractant with 9-0DA at a short range (Brockmann et al., 2006). The value of HVA and HOB for drones is also questionable: virgin queens do not produce HVA and very little HOB in comparison to mated queens (Plettner et al., 1997). Therefore, these compounds could be only necessary for the induction of workers' retinue behavior by mated queens, and not for drone attraction to virgin queens. This emphasizes again the particular case of the queen pheromone in honeybees, in which the same components can have different roles depending on the receiver being a drone or a worker. Caution is, however, necessary because two macroglomeruli of the drone AL (MG3 and MG4) were not accessible to our imaging study and may respond to these queen signals despite the fact that the corresponding Ors have not been identified at the level of the drone antennae (Wanner et al., 2007). As discussed above for workers, the use of multi-photonic microscopy and electrophysiological measurements of labeled neurons could help understanding more about the respective role of the four macroglomeruli in the drone AL.

In queens, which are females genetically identical to workers but which were fed differently, both qualitatively and quantitatively, during development, AL organization is similar to that of workers (Arnold et al., 1988; our observations). Despite clear anatomical differences (queens have a much longer abdomen, different mouthparts, a lack of pollencollecting structures on the legs, fewer antennal pore plates, and a different development of the glandular system compared to workers; Winston, 1987) the AL of queens presents a number of glomeruli which is similar to that of workers ( 155 in queens vs. $\sim 165$ in workers, Figure 4). One particularly conspicuous glomerulus of the dorsal region belonging to the tract $\mathrm{T} 1$ (termed 'MG' in Figure 4; see below) has a volume about 3-4 times larger than that of other glomeruli. This glomerulus's volume, relative to the rest of the antennal lobe, is higher in queens - especially mated - than in workers, in which its counterpart T1-44 (see Figure 4) is already voluminous (Flanagan and Mercer, 1989; Galizia et al., 1999a). For these reasons, it has been postulated that this glomerulus could 
represent a female macroglomerulus, which could be dedicated to the recognition of species-specific signals (Arnold et al., 1988). It is interesting to note that this putative macroglomerulus is placed in a similar position in the antennal lobe of queens (and workers) as three out of the four drone macroglomeruli, i.e., on the more dorsal part of the T1 region. Future behavioral and physiological work using calcium imaging should study the possible involvement of this female putative macroglomerulus in drone or brood pheromone detection and processing.

\section{Processing in higher-order olfactory centers: mushroom body (MB) and lateral horn (LH)}

Both in the fruit fly and in the honeybee, higher-brain centers like the MBs are known to be important sites for olfactory-based decision-making and to house olfactory memory traces (Davis, 2005; Hammer and Menzel, 1998; Zars, 2000). Very little is, however, known about how pheromonal information is represented and processed therein. We have seen that only in the case of the drone, we could demonstrate the existence of a labeledline for a pheromonal component, 9-ODA from ORNs to the AL. In workers, such a labeled-line may exist in AL regions that are not yet accessible to optical imaging, but a proof is still lacking. On the other hand, we have ample demonstration of across-pattern processing for general odorants both in workers and in drones. More surprisingly, our recordings suggest that this may also be the case for social pheromones, for which no dedicated glomeruli have been yet found. One interesting hypothesis is that specific recognition of pheromones, in particular the social ones, would take place at higher processing levels, i.e., downstream the AL network.

As found in the drone, there appears to be a clear segregation between 9-ODA responding glomeruli and floral/social odor responding glomeruli. Based on the clear anatomical segregation of projections from the $A L$ to higher centers described above (see "Basic organization of the honeybee olfactory system" section), a possible hypothesis would be that 9-ODA and non-pheromonal information would follow different pathways, and that specific projection areas within the drone MBs and LH are devoted to the processing of this QMP component. Likewise, in the case of the worker, pheromone information could follow a different route and project to specific areas within higher-order centers. Although evidence is missing in the case of drones, electrophysiological recordings performed on worker PNs have shown that no clear separation exists between floral odors and worker-emitted pheromones (Abel et al., 2001; Galizia and Kimmerle, 2004; Müller et al., 2002; Sun et al., 1993). PNs both from the I-ACT and from the m-ACT (see "Basic organization of the honeybee olfactory system" section) respond to floral odors and also to odors like geraniol (aggregation), citral (aggregation), isoamyl acetate (alarm) or 2-heptanone (alarm), making it unlikely that one of these two tracts is specifically involved in pheromonal processing. Rather, it is currently believed that these two main tracts of PNs are involved in general odor coding, providing higher areas with differential information: $m-A C T$ neurons would code odors by latency differences or patterns of inhibitory and excitatory phases while I-ACT neurons would code odors by spike-rate differences (Müller et al., 2002). Moreover, it must be noted that most projection neurons of the $\mathrm{m}$ - and I-ACT are uniglomerular, so that if we do not find specific glomeruli for pheromones in workers, it is unlikely that some of these PN would carry a specific pheromonal signal to higher centers.

In the worker MBs, calcium imaging recordings have shown that odors also evoke combinatorial activity patterns, as in the AL (Szyszka et al., 2005). However, the MB spatial patterns are consistently sparser than those found at the AL. Such a sparsening of odorant representation occurs in the transmission from PNs to Kenyon cells (KCs), the constitutive neurons of MBs. Many PNs feed onto each Kenyon cell, but imaging showed that activated KCs are highly odor specific and exhibit sharpened temporal responses, probably due to the presence of a broad loop of inhibitory neurons acting on KCs (Szyszka et al., 2005). In the locust, such an inhibitory input on KCs, which also results in sparsening of odor representation in the $\mathrm{KCs}$, is provided by gabaergic neurons from the lateral horn (Pérez Orive et al., 2002). How this sparsening and KC temporal sharpening affects pheromone vs. floral odor representation in the MBs remains unknown. It is conceivable, that particular KCs could 'recognize', specific combinations of activated projection neurons, which would indicate that the detected stimulus is a pheromone. In the only study performed on the worker KCs (Szyszka et al., 2005), only non-pheromonal odors were tested, so that future work is necessary to look for the existence of such pheromonespecific KCs. It must be emphasized that MB extrinsic neurons (i.e., neurons that act as output of the MBs), like the Pe-1 neuron, typically respond to pheromones (2-heptanone, citral; Rybak and Menzel, 1998) as do MB feedback neurons (i.e., neurons that being output of the MBs feed again onto these structures; geraniol, citral; Grünewald, 1999). However, they do not respond specifically to these compounds, so that it is not clear whether such responses are related to the general olfactory system, or to pheromone processing per se.

Less information is available from ml-ACT neurons which project to the $\mathrm{LH}$ and lateral protocerebrum. These neurons could be especially interesting in the context of pheromone processing because they are mostly multiglomerular, and could thus detect a specific pattern of activity and code the pheromonal nature of stimuli. The available data suggests that they can respond to pheromones like geraniol or citral, but these stimuli mostly provoke an inhibition of spontaneous activity (Abel et al., 2001). Thus, although the bee olfactory system clearly presents several parallel olfactory processing lines (m-, l-, and $\mathrm{ml}$ - ACT and their corresponding projection areas), functional data does not point to the dedication of one of these pathways to pheromonal processing. This, however, does not preclude that within a particular pathway, pheromone-dedicated neurons could project to a specific area within the MB or LH.

The role of the honeybee LH in olfactory processing remains currently unknown. Due to its unstructured arrangement, which makes functional recordings of neural activity difficult, less attention has been paid to this structure. In the fruit fly, however, recent neuroanatomical work could reconstruct putative maps of olfactory input to the MBs and to the $\mathrm{LH}$ (Jefferis et al., 2007). In this species, the response spectra of individual ORNs to odors are known (Hallem and Carlson, 2006; Hallem et al., 2004). Moreover, glomeruli receiving input from ORNs carrying each receptor have been carefully mapped (Couto et al., 2005; Fishilevich and Vosshall, 2005) and the exact projection of individual uniglomerular PNs from identified glomeruli has been retraced so that it is now possible to predict where information gained by each olfactory receptor is projected to. Interestingly, reconstructed olfactory maps at the level of the LH predict a clear segregation between candidate pheromone-responsive PNs and fruit odor-responsive PNs (Jefferis et al., 2007). Such functional segregation was not apparent in the MBs, although PNs from different glomeruli also project there in at least 17 different areas (Jefferis et al., 2007). These data, which still await physiological confirmation, suggest that, at least in the Drosophila LH, particular subregions may code the biological nature of olfactory stimuli. If a similar organization of the olfactory circuit exists in fruit flies and honeybees (and there are indeed several remarkable parallels), one could expect the honeybee LH to exhibit pheromone processing regionalization. Here again, novel anatomical and physiological experiments are required to address this question.

\section{CONCLUSION}

The honeybee possesses an extremely rich and complex social communication system, which highly relies on olfactory communication and uses a wide repertoire of different pheromones, produced mainly by the female castes, workers and queen. Behavioral and physiological effects of these pheromones on workers and drones are well established, some of which can be measured in the laboratory. The intensive previous work that has described the different elements of the olfactory circuits, as well as the accessibility of this animal model to physiological recording methods, like electrophysiology and optical imaging, make it a stimulating model for the study of the neurobiological basis of pheromonal processing. As we have seen, however, important information is still missing regarding the individual 
neurons involved in pheromonal detection. First, except for 9-0DA (Wanner et al., 2007), we still do not know the receptor proteins involved in the detection of sexual and social pheromones in this species. This is important, since, as shown in Figure 1, determining the specificity of individual receptors is critical for detecting labeled-lines. We expect that heterologous expression of Or proteins in Xenopus 0ocytes as done by Wanner et al. (2007) will help progressing in this direction, if carried out on a wider scale. Second, it will be important to progress in the mapping of one-to-one relationships between particular pheromone receptor types and their glomerular projection, as well as between output neurons from these glomeruli and their more central projections. We believe that future work combining molecular biology, neuroanatomy, electro- and opto-physiological recordings will allow bridging this gap in our current knowledge.

As for now, the picture emerging from the available data is that of a system in which both dedicated labeled-line processing and acrossfiber pattern coding coexist. Labeled-line processing applies to the case of 9-ODA in drones, starting with a dedicated antennal Or (Wanner et al. 2007) and continuing with a highly 9-0DA specific macroglomerulus in the $\mathrm{AL}$ (Sandoz, 2006). It is probable that more such labeled-lines exist in the drone for other components of the queen sex pheromone, as there are three other drone-specific Ors and three other macroglomeruli, for which we do not know the key odorants. Such a dedicated pathway remains to be followed at higher levels of the drone olfactory circuit in particular in the MBs and LH. In other traditional insect models for the study of pheromonal vs. non-pheromonal processing, there is also growing evidence that pheromone processing, both sexual and social, also relies on a combinatorial strategy at some point of its processing. This is particularly true for the male macroglomerular complex (Christensen and Hildebrand, 2002). For instance, in the moth Heliothis virescens, recognition of the sexual partner is based on the detection of four main compounds: They are detected according to a labeled-line system, by four specific receptor neuron types, each projecting into one of four MGC compartments (Berg et al., 1998; Hansson et al., 1995). The two largest compartments receive input from neurons carrying information used in behavioral attraction to the female, while the two smallest from neurons responsible for blocking this attraction. Indeed, each glomerulus within the macroglomerular complex responds in imaging experiments to one of the compounds (Galizia et al., 2000). However, recognition by the Heliothis male of a female of the right species critically depends on integration of information both from the intra-specific attraction-based compounds and from the inter-specific repulsion-based compounds. This suggests that downstream of the initial labeled-lines, across-fiber integrators have to extract the right combinations of the different compounds, before probably feeding onto further dedicated labeled-lines for specific across-MGC compartment combinations (Galizia et al., 2000). Such a situation may well exist in the drone, with central neurons integrating information from several macroglomeruli.

In the honeybee, across-fiber pattern certainly applies to the processing of non-pheromonal odors (flower odors) and may also apply to social pheromone components both in drones and workers, as suggested by imaging recordings. However, it must be emphasized here that the behavioral responses to these social pheromones are quite specific (Free, 1987). Thus, it is probable that specific social-pheromone units do exist somewhere in the bee brain, which assign to these pheromones their specific meaning. Several possibilities exist. First, because until now optical recordings were limited to about 40 glomeruli at the frontal surface of the AL, there is still the possibility that social pheromone-specific glomeruli exist in this structure. Conversely, another system may exist, in which pheromone-specific units would only be found in higher-brain centers like the MBs or LH, i.e., a system combining peripheral acrossfiber pattern with more central labeled-line units.

These examples show that labeled-line and across-fiber pattern are not each limited to pheromonal and general odor processing respectively, but that both types of biological signals may rely on both strategies at different processing levels. Because studies on odorant processing in the bee central nervous system have mainly focused on the $\mathrm{AL}$, areas like the MBs and $\mathrm{LH}$ have been left mostly unexplored. We expect that the development of novel microscopic techniques (like multi-photon microscopy allowing accessing neural structures in depth and with better resolution) and molecular genetics will help improving our knowledge of the neural basis of insects' olfactory communication. The honeybee, as a model system for addressing these questions, certainly deserves our interest.

\section{CONFLICT OF INTEREST STATEMENT}

The authors declare that the research was conducted in the absence of any commercial or financial relationships that could be construed as a potential conflict of interest.

\section{ACKNOWLEDGEMENT}

The authors would like to thank all the members of the Bee group in the Research Center for Animal Cognition for an incentive and constructive scientific environment.

\section{REFERENCES}

Abel, R., Rybak, J., and Menzel, R. (2001). Structure and response patterns of olfactory interneurons in the honeybee, Apis mellifera. J. Comp. Neurol. 437, 363-383.

Arnold, G., Budharugsa, S., and Masson, C. (1988). Organization of the antennal lobe in the queen honey bee Apis mellifera L. (Hymenoptera: Apidae). Int. J. Insect Morphol. Embryol. 17, 185-195.

Arnold, G., Le Conte, Y., Trouiller, J., Hervet, H., Chappe, B., and Masson, C. (1994). Inhibition of worker honeybee ovaries development by a mixture of fatty acid esters from larvae. C. R. Acad. Sci. Paris 317, 511-515.

Arnold, G., Masson, C., and Budharugsa, S. (1985). Comparative study of the antennal lobes and their afferent pathways in the worker bee and the drone (Apis mellifera). Cell Tissue Res. 242, 593-605

Ayasse, M., Paxton, R. J., and Tengo, J. (2001). Mating behavior and chemical communication in the order Hymenoptera. Annu. Rev. Entomol. 46, 31-78.

Barbier, M., and Lederer, E. (1960). Structure chimique de la substance royale de la reine d'abeille Apis mellifera L. C. R. Acad. Sci. Paris 251, 1131-1135.

Benton, R., Sachse, S., Michnick, S. W., and Vosshall, L. B. (2006). Atypical membrane topology and heteromeric function of Drosophila odorant receptors in vivo. PLoS Biol. 4, e20.

Berg, B. G., Almaas, T. J., Bjaalie, J. G., and Mustaparta, H. (1998). The macroglomerular complex of the antennal lobe in the tobacco budworm moth Heliothis virescens: specified subdivision in four compartments according to information about biologically significant compounds. J. Comp. Physiol. A 183, 669-682.

Bicker, G., Kreissl, S., and Hofbauer, A. (1993). Monoclonal-antibody labels olfactory and visual pathways in Drosophila and Apis brains. J. Comp. Neurol. 335, 413-424.

Blomquist, G. J., Chu, A. J., and Remaley, S. (1980). Biosynthesis of wax in the honeybee, Apis mellifera. L. Insect Biochem. 10, 313-321.

Blum, M. S., Boch, R., Doolittle, E., Tribble, M. T., and Traynham, J. G. (1971). Honey bee sex attractant: conformational analysis, structural specificity, and lack of masking activity of congeners. J. Insect Physiol. 17, 349-364.

Boch, R., Shearer, D. A., and Stone, B. C. (1962). Identification of iso-amyl acetate as an active component in the sting pheromone of the honey bee. Nature 195, 1018-1020.

Boch, R., Shearer, D. A., and Young, J. C. (1975). Honeybee pheromones: field tests of natural and artificial queen substance. J. Chem. Ecol. 1, 133-148.

Boeckh, J., Kaissling, K. E., and Schneider, D. (1965). Insect olfactory receptors. Cold Spring Harb. Symp. Quant. Biol. 30, 263-280

Brandt, R., Rohlfing, T., Rybak, J., Krofczik, S., Maye, A., Westerhoff, M., Hege, H. C., and Menzel, R. (2005). Three-dimensional average-shape atlas of the honeybee brain and its applications. J. Comp. Neurol. 492, 1-19.

Breed, M. D., Guzman Novoa, E., and Hunt, G. J. (2004). Defensive behavior of honey bees: organization, genetics, and comparisons with other bees. Annu. Rev. Entomol. 49, 271-298.

Brockmann, A., and Brückner, D. (2001). Structural differences in the drone olfactory system of two phylogenetically distant Apis species, A. florea and A. mellifera. Naturwissenschaften 88, 78-81.

Brockmann, A., Brückner, D., and Crewe, R. (1998). EAG responses of worker and drone honeybees Apis mellifera to pheromones of the mandibular gland of the queen Naturwissenschaften 85, 283-285.

Brockmann, A., Dietz, D., Spaethe, J., and Tautz, J. (2006). Beyond 9-0DA: sex pheromone communication in the European honey bee Apis mellifera L. J. Chem. Ecol. 32 657-667.

Butler, C. G., Callow, R. K., and Johnson, N. C. (1961). The isolation and synthesis of queen substance, 9-oxo-dec-trans-2-enoic acid, a honeybee pheromone. Proc. $R$. Soc. Entomol. Soc. 155, 417-432.

Butler, C. G., and Fairey, E. M. (1964). Pheromones of the honeybee: biological studies of the mandibular gland secretion of the queen. J. Apic. Res. 3, 65-76. 
Châline, N., Sandoz, J. C., Martin, S. J., Ratnieks, F. L., and Jones, G. R. (2005). Learning and discrimination of individual cuticular hydrocarbons by honeybees (Apis mellifera). Chem. Senses 30, 327-335.

Christensen, T. A., and Hildebrand, J. G. (2002). Pheromonal and host-odor processing in the insect antennal lobe: how different? Curr. Opin. Neurobiol. 12, 393-399.

Collins, A. M., and Blum, M. S. (1982). Bioassay of compounds derived from the honeybee sting. J. Chem. Ecol. 8, 463-470.

Collins, A. M., and Blum, M. S. (1983). Alarm responses caused by newly identified compounds derived from the honeybee sting. J. Chem. Ecol. 9, 57-65.

Couto, A., Alenius, M., and Dickson, B. J. (2005). Molecular, anatomical, and functional organization of the Drosophila olfactory system. Curr. Biol. 15, 1535-1547.

Dahanukar, A., Hallem, E. A., and Carlson, J. R. (2005). Insect chemoreception. Curr. Opin. Neurobiol. 15, 423-430.

Davis, R. L. (2005). Olfactory memory formation in Drosophila: from molecular to systems neuroscience. Annu. Rev. Neurosci. 28, 275-302.

Deisig, N., Giurfa, M., Lachnit, H., and Sandoz, J. C. (2006). Neural representation of olfactory mixtures in the honeybee antennal lobe. Eur. J. Neurosci. 24, 1161-1174.

El-Sayed, A. M., Suckling, D. M., Wearing, C. H., and Byers, J. A. (2006). Potential of mass trapping for long-term pest management and eradication of invasive species. J. Econ. Entomol. 99, 1550-1564.

Esslen, J., and Kaissling, K. E. (1976). Zahl und Verteilung antennaler Sensillen bei der Honigbiene (Apis mellifera L.). Zoomorphology 83, 227-251.

Ferveur, J. F. (2005). Cuticular hydrocarbons: their evolution and roles in Drosophila pheromonal communication. Behav. Genet. 35, 279-295.

Fishilevich, E., and Vosshall, L. B. (2005). Genetic and functional subdivision of the Drosophila antennal lobe. Curr. Biol. 15, 1548-1553.

Flanagan, D., and Mercer, A. R. (1989). An atlas and 3-D reconstruction of the antennal lobes in the worker honey bee, Apis mellifera (Hymenoptera, Apidae). Int. J. Insect Morphol. Embryol. 18, 145-159.

Fonta, C., Sun, X. J., and Masson, C. (1993). Morphology and spatial-distribution of bee antennal lobe interneurons responsive to odors. Chem. Senses 18, 101-119.

Forêt, S., and Maleska, R. (2006). Function and evolution of a gene family encoding odorant binding-like proteins in a social insect, the honey bee (Apis mellifera) Genome Res. 16, 1404-1413.

Free, J. B. (1987). Pheromones of Social Bees. Ithaca, NY, Comstock

Galizia, C. G. (2008). Insect Olfaction. In The Senses, A comprehensive reference, Vol. 1 Olfaction \& Taste, D. V. Smith, S. Firestein, and G. K. Beauchamp, eds (London, UK Elsevier), 4.41, pp. 725-769.

Galizia, C. G., Joerges, J., Küttner, A., Faber, T., and Menzel, R. (1997). A semi-in-vivo preparation for optical recording of the insect brain. J. Neurosci. Methods 76 $61-69$.

Galizia, C. G., and Kimmerle, B. (2004). Physiological and morphological characterization of honeybee olfactory neurons combining electrophysiology, calcium imaging and confocal microscopy. J. Comp. Physiol. A 190, 21-38.

Galizia, C. G., Mcllwrath, S. L., and Menzel, R. (1999a). A digital three-dimensional atlas of the honeybee antennal lobe based on optical sections acquired by confocal microscopy. Cell Tissue Res. 295, 383-394.

Galizia, C. G., and Menzel, R. (2001). The role of glomeruli in the neural representation of odours: results from optical recording studies. J. Insect Physiol. 47, 115-130.

Galizia, C. G., Sachse, S., Rappert, A., and Menzel, R. (1999b). The glomerular code for odor representation is species specific in the honeybee Apis mellifera. Nat. Neurosci. 2, 473-478.

Galizia, C. G., Sachse, S., and Mustaparta, H. (2000). Calcium responses to pheromones and plant odours in the antennal lobe of the male and female moth Heliothis vires cens. J. Comp. Physiol. A 186, 1049-1063.

Galizia, C. G., and Vetter, R. S. (2004). Optical methods for analyzing odor-evoked activity in the insect brain. In Methods in Insect Sensory Neuroscience, T. A. Christensen, ed (Boca Raton, FL, CRC Press), pp. 345-392.

Getz, W. M., and Smith, K. B. (1987). Olfactory sensitivity and discrimination of mixtures in the honeybee Apis mellifera. J. Comp. Physiol. A 160, 239-245.

Giurfa, M. (2003). Cognitive neuroethology: dissecting non-elemental learning in a honeybee brain. Curr. Opin. Neurobiol. 13, 726-735.

Giurfa, M. (2007). Behavioral and neural analysis of associative learning in the honeybee: a taste from the magic well. J. Comp. Physiol. A 193, 801-824.

Giurfa, M., and Núñez, J. A. (1992). Honeybees mark with scent and reject recently visited flowers. Oecologia 89, 113-117.

Gronenberg, W. (2001). Subdivisions of hymenopteran mushroom body calyces by their afferent supply. J. Comp. Neurol. 435, 474-489.

Grozinger, C. M., Sharabash, N. M., Whitfield, C. W., Robinson, G. E. (2003). Pheromonemediated gene expression in the honey bee brain. Proc. Natl. Acad. Sci. U.S.A. 100 Suppl 2, 14519-14525.

Grünewald, B. (1999). Morphology of feedback neurons in the mushroom body of the honeybee, Apis mellifera. J. Comp. Neurol. 404, 114-126

Guerrieri, F., Schubert, M., Sandoz, J. C., and Giurfa, M. (2005). Perceptual and neural olfactory similarity in honeybees. PLoS Biol. 3, e60, 1-15.

Hallem, E. A., and Carlson, J. R. (2006). Coding of odors by a receptor repertoire. Cell $125,143-160$.

Hallem, E. A., Ho, M. G., and Carlson, J. R. (2004). The molecular basis of odor coding in the Drosophila antenna. Cell 117, 965-979.
Hammer, M., and Menzel, R. (1998). Multiple sites of associative odor learning as revealed by local brain microinjections of octopamine in honeybees. Learn. Mem. $5,146-156$

Hansson B. S., Almaas T. J., and Anton S. (1995). Chemical communication heliothine moths $V$. Antennal lobe projection patterns of pheromonedetecting olfactory receptor neurons in the male Heliothis virescens (Lepidoptera: Noctuidae). J. Comp. Physiol. A 177, 535-543.

Hoover, S. E., Keeling, C. I., Winston, M. L., and Slessor, K. N. (2003). The effect of queen pheromones on worker honey bee ovary development. Naturwissenschaften 90 477-480.

Jefferis, G. S., Potter, C. J., Chan, A. M., Marin, E. C., Rohlfing, T., Maurer, C. R. Jr, and Luo, L. (2007). Comprehensive maps of Drosophila higher olfactory centers: spatially segregated fruit and pheromone representation. Cell 128, 1187-1203.

Joerges, J., Küttner, A., Galizia, G. C., and Menzel, R. (1997). Representation of odours and odour mixtures visualized in the honeybee brain. Nature 387, 285-288.

Jutsum, A. R., and Gordon, R. F. S. (1989). Insect pheromones in plant protection, New York, Academic Press, 386 pp.

Kaissling, K. E. (1987). R. H. Wright Lectures on Insect Olfaction. K. Colbow, ed. (Burnaby, Simon Fraser University), $190 \mathrm{pp}$.

Kaissling, K. E., and Renner, M. (1968). Antennale Rezeptoren für queen substance und Sterzelduft bei der Honigbiene. Z. Vgl. Physiol. 59, 357-361.

Karlson, P., and Luscher, M. (1959). Pheromones: a new term for a class of biologically active substances. Nature 183, 55-56.

Keeling, C. I., Slessor, K. N., Higo, H. A., and Winston, M. L. (2003). Isolation and identification of new components of the honey bee (Apis mellifera L.) queen retinue pheromone. Proc. Natl. Acad. Sci. U.S.A. 100, 4486-4491.

Kelber, C., Rössler, W., and Kleineidam, C. J. (2006). Multiple olfactory receptor neurons and their axonal projections in the antennal lobe of the honeybee Apis mellifera. J. Comp. Neurol. 496, 395-405.

Kirschner, S., Kleineidam, C. J., Zube, C., Rybak, J., Grünewald, B., and Rössler, W. (2006). Dual olfactory pathway in the honeybee, Apis mellifera. J. Comp. Neurol. 499, 933-952.

Knudsen, J. T., Tollsten, L., and Bergström, L. G. (1993). Floral scents - a checklist of volatile compounds isolated by head-space techniques. Phytochemistry 33 , 253-280.

Lacaille, F., Hiroi, M., Twele, R., Inoshita, T., Umemoto, D., Maniere,G., Marion-Poll, F., Ozaki, M., Francke, W., Cobb, M., Everaerts, C., Tanimura, T., and Ferveur, J. F (2007) An inhibitory sex pheromone tastes bitter for Drosophila males. PLOS ONE 2, e661.

Lacher, V., and Schneider, D. (1963). Elektrophysiologischer Nachweis der Riechfunktion von Porenplatten auf den Antennen der Drohne und der Arbeitsbiene (Apis mellifica L.) Z. Vgl. Physiol. 47, 274-278.

Laurent, S., Masson, C., and Jakob, I. (2002). Whole-cell recording from honeybee olfactory receptor neurons: ionic currents, membrane excitability and odourant response in developing workerbee and drone. Eur. J. Neurosci. 15, 1139-1152.

Le Conte, Y., Sreng, L., and Poitout, S. H. (1995). Brood pheromone can modulate the feeding behavior of Apis mellifera workers (Hymenoptera: Apidae). J. Econ. Entomol. 88, 798-804.

Lensky, Y., Cassier, P., Notion, M., Delorme-Joulie, C., and Levinsohn, M. (1985). Pheromonal activity and fine structure of the mandibular glands of honeybee drones (Apis mellifera L.) (Insecta, Hymenoptera, Apidae). J. Insect Physiol. 31, 265-276.

Masson, C., and Mustaparta, H. (1990). Chemical information processing in the olfactory system of insects. Physiol. Rev. 70, 199-245.

Mobbs, P. G. (1982). The brain of the honeybee Apis mellifera. 1. The connections and spatial-organization of the mushroom bodies. Philos. Trans. R. Soc. Lond. B Biol. Sci. 298, 309-354.

Mohammedi, A., Paris, A., Crauser, D., and Le Conte, Y. (1998). Effect of aliphatic esters on ovary development of queenless bees (Apis mellifera L.). Naturwissenschaften 85, 455-458.

Müller, D., Abel, R., Brandt, R., Zockler, M., and Menzel, R. (2002). Differential parallel processing of olfactory information in the honeybee, Apis mellifera L. J. Comp. Physiol. A 188, 359-370.

Mustaparta, H. (1996). Central mechanisms of pheromone information processing Chem. Senses 21, 269-275.

Olberg, R. M. (1983). Pheromone-triggered flip-flopping interneurons in the ventral nerve cord of the silkworm moth, Bombyx mori. J. Comp. Physiol. A 152, 297-307.

Pareto, A. (1972). Spatial-distribution of sensory antennal fibers in central nervous-system of worker bees. Z. Zellforsch. Mikrosk. Anat. 131, 109-140.

Perez Orive, J., Mazor, 0., Turner, G. C., Cassenaer, S., Wilson, R. I., Laurent, G. (2002). Oscillations and sparsening of odor representations in the mushroom body. Science 297, 359-365.

Pickett, J. A., Williams, I. H., and Martin, A. P. (1982). (Z)-11-eicosen-1-ol, an important new pheromonal component from the sting of the honey bee, Apis mellifera $\mathrm{L}$. (Hymenoptera, Apidae). J. Chem. Ecol. 8, 163-175.

Pickett, J. A., Williams, I. H., Martin, A. P., and Smith, M. C. (1980). Nasonov pheromone of the honeybee, Apis mellifera L. (Hymenoptera: Apidae). Part 1. Chemical characterization. J. Chem. Ecol. 6, 425-434.

Plettner, E. (2002). Insect pheromone olfaction: new targets for the design of speciesselective pest control agents. Curr. Med. Chem. 9, 1075-1085. 
Plettner, E., Otis, G. W., Wimalaratne, P. D. C., Winston, M. L., Slessor, K. N., Pankiw, T., and Punchihewa, P. W. K. (1997). Species- and caste determined mandibular gland signals in honeybees (Apis). J. Chem. Ecol. 23, 363-377.

Robertson, H. M., and Wanner, K. W. (2006). The chemoreceptor superfamily in the honey bee, Apis mellifera: expansion of the odorant, but not gustatory, receptor family. Genome Res. 16, 1395-1403.

Rutowski, R. L. (1981). The function of pheromones. J. Chem. Ecol. 7, 481-483.

Rybak, J., and Menzel, R. (1998). Integrative properties of the Pe-1 neuron, a unique mushroom body output neuron. Learn. Mem. 5, 133-145.

Sachse, S., and Galizia, C. G. (2002). Role of inhibition for temporal and spatial odor representation in olfactory output neurons: a calcium imaging study. J. Neurophysiol. 87, 1106-1117.

Sachse, S., Rappert, A., and Galizia, C. G. (1999). The spatial representation of chemica structures in the antennal lobe of honeybees: steps towards the olfactory code. Eur. J. Neurosci. 11, 3970-3982.

Sandoz, J. C. (2006). Odour-evoked responses to queen pheromone components and to plant odours using optical imaging in the antennal lobe of the honey bee drone Apis mellifera L. J. Exp. Biol. 209, 3587-3598.

Sandoz, J. C., Pham-Delègue, M. H., Renou, M., and Wadhams, L. J. (2001). Asymmetrical generalisation between pheromonal and floral odours in appetitive olfactory conditioning of the honey bee (Apis mellifera L.). J. Comp. Physiol. A 187, 559-568.

Shearer, D. A., and Boch, R. (1965). 2-heptanone in the mandibular gland secretion of the honey bee. Nature 206, 530

Skirkeviciene, Z., and Skirkevicius, A. (1994). Worker bee and drone (Apis melliferaL.) behavior and functional reorganization of their olfactory receptors. Pheromones 4, 83-92.

Slessor, K. N., Kaminski, L. A., King, G. G. S., Borden, J. H., and Winston, M. L. (1988) Semiochemical basis of the retinue response to queen honey bees. Nature 332 , 354-356.

Smith, B. H. (1991). The olfactory memory of the honeybee Apis mellifera I. Odorant modulation of short- and intermediate-term memory after single-trial conditioning. J. Exp. Biol. 161, 367-382.
Strausfeld, N. J. (2002). Organization of the honey bee mushroom body: representation of the calyx within the vertical and gamma lobes. J. Comp. Neurol. 450, 4-33.

Sun, X. J., Fonta, C., and Masson, C. (1993). Odour quality processing by bee antennal lobe interneurones. Chem. Senses 18, 355-377.

Szyszka, P., Ditzen, M., Galkin, A., Galizia, C. G., and Menzel, R. (2005). Sparsening and temporal sharpening of olfactory representations in the honeybee mushroom bodies. J. Neurophysiol. 94, 3303-3313.

The Honeybee Genome Sequencing Consortium (2006). Insights into social insects from the genome of the honeybee Apis mellifera. Nature 443, 931-949.

Thom, C., Gilley, D. C., Hooper, J., Esch, H. E. (2007). The scent of the waggle dance. PLOS Biol. 5, e228.

van der Meer, R. K., Wilson, M. L., Breed, M. D., and Espelie, K. E. (1998). Pheromone communication in social insects (Oxford, C0, Westview Press), pp. 368.

Vareschi, E. (1971). Duftunterscheidung bei der Honigbiene - Einzelzell-Ableitungen und Verhaltensreaktionen. Z. Vgl. Physiol. 75, 143-173.

von Frisch, K. (1967). The Dance Language and Orientation of Bees. Cambridge, MA, Harvard University Press.

Vergoz, V., Schreurs, H. A., and Mercer, A. R. (2007) Queen pheromone blocks aversive learning in young worker bees. Science 317, 384-386.

Vetter, R. S., and Visscher, P. K. (1997). Influence of age on antennal response of male honey bees, Apis mellifera, to queen mandibular pheromone and alarm pheromone component. J. Chem. Ecol. 23, 1867-1880.

Wanner, K. W., Nichols, A. S., Walden, K. K., Brockmann, A., Luetje, C. W., and Robertson, H.M. (2007). A honey bee odorant receptor for the queen substance 9-0xo-2-decenoic acid. Proc. Natl. Acad. Sci. U.S.A. 104, 14383-14388.

Wilson, E. 0. (1970). Chemical communication within animal species. In Chemical Ecology, B. Sandheimer and J. B. Simeone eds, (New York, NY, Academic Press).

Winston, M. L. (1987). The biology of the honey bee. Cambridge, MA, Harvard University Press, $281 \mathrm{pp}$.

Zars, T. (2000). Behavioral functions of the insect mushroom bodies. Curr. Opin. Neurobiol. 10, 790-795. 